\title{
Facebook: um novo locus para a manifestação de uma perda significativa
}

\author{
Regina Szylit Bousso ${ }^{\mathrm{a}}$, Daniel Ramos ${ }^{\mathrm{a}}$, Heloísa Cristina Figueiredo Frizzo ${ }^{\mathrm{b}}$ \\ Maiara Rodrigues dos Santos ${ }^{\mathrm{a}}$, Fernando Bousso ${ }^{c}$ \\ ${ }^{a}$ Escola de Enfermagem, Universidade de São Paulo, SP, Brasil. ; ' Universidade Federal do Triângulo Mineiro - UFTM, Uberaba, MG, \\ Brasil; ' University of London, London, UK
}

Resumo: Os objetivos deste estudo foram explorar a utilização da rede social Facebook pelos enlutados devido à morte de um ente querido e analisar o compartilhamento de conteúdos no perfil do falecido, postumamente mediada por esta plataforma. Trata-se de um estudo qualitativo no qual foi utilizado análise de conteúdo para tratamento dos dados. Ao total, foram analisados 195 comentários postados no perfil do falecido postumamente durante 0 primeiro mês da morte dele. Foi possível identificar categorias temáticas como comentários ao falecido, sentimentos, emoções, indicadores de estratégias de enfrentamento do luto, crenças religiosas e homenagens. As redes sociais virtuais impulsionam a manifestação de sentimentos usualmente retraídos e permitem a interação social de temas dificilmente tratados abertamente, favorecendo a elaboração do luto de pacientes, familiares e profissionais que enfrentam o processo de morte/morrer e luto.

Palavras-chave: luto, internet, interação social.

\section{Introdução}

O compartilhamento do luto na Internet tem sido observado com bastante frequência nas comunidades virtuais, em especial nas redes sociais. O avanço da chamada sociedade da informação e da comunicação se faz presente em todos os campos do saber, desestruturando a ordem tradicional na lógica de produção, disseminação e uso de informações e conhecimentos. Desta forma, também na área da saúde, esse avanço provoca mudanças nas formas de pensar o processo saúde-doença. Diante dessa perspectiva, neste estudo é relevante compreender o uso da rede social Facebook pelos enlutados devido à morte de um ente querido e analisar o compartilhamento de conteúdos no perfil do falecido, postumamente mediada por esta plataforma.

O Facebook é um sítio eletrônico no qual as pessoas criam um perfil pessoal, adicionam outros usuários como amigos e trocam mensagens e conteúdos de forma geral. A plataforma foi criada em 2004, por Mark Zuckerberg, Eduardo Saverin, Dustin Moskovitz e Chris Hughes. Atualmente, qualquer indivíduo pode participar desta rede social, a partir dos interesses pessoais e profissionais. $\mathrm{O}$ Facebook oferece uma vasta lista de ferramentas e aplicativos que permitem aos usuários comunicar e partilhar informações, adicionar fotografias, vídeos, comentários, ligações, enviar mensagens, integrar com outros websites, dispositivos móveis e outras tecnologias. Ainda, permite o controle de privacidade, ao selecionar qual informação e com quem deseja compartilhar (Educause Learning Initiative, 2007).

A morte sempre suscitou emoções que se socializaram em práticas fúnebres. A angústia que a consciência

1 Autor correspondente: Regina Szylit Bousso, e-mail: szylit@usp.br da finitude tem provocado no ser humano ao longo dos tempos é tão intensa que para o sobrevivente, a aceitação da morte é um processo penoso, especialmente na cultura ocidental (Silvestre \& Aguilera, 2008). A Internet tem sido uma expansão do espaço offline e questões concernentes à vida e à morte migraram para dentro do mundo online, na busca pela expressão do sentimento de luto.

Negrini (2010) propõe a reflexão sobre o tratamento da morte na comunidade do Orkut "Profiles de Gente Morta", investigando perfis de pessoas mortas em situações trágicas e inesperadas, a partir de um estudo etnográfico na comunidade virtual. Essa comunidade permite que as pessoas possam manifestar o que pensam sobre a morte, o que faz do espaço virtual um lugar onde o público tem autonomia para fazer as discussões que o mundo offline considera proibidas e as interdita no cotidiano.

Considerando a necessidade de compreender essa nova forma de expressão do luto, observa-se que mais estudos nessa área são importantes e podem ajudar profissionais de saúde a aprimorarem suas intervenções para entender e acompanhar àqueles que enfrentam o processo de morte/morrer e luto.

O enfrentamento, segundo Lazarus e Folkman (1984), é definido como "esforços cognitivos e comportamentais em constante mudança, com objetivo de manejar (minimizar, evitar ou tolerar) demandas específicas internas e/ou externas que são avaliadas como sobrecarga ou excedendo os recursos pessoais" (p. 141). Comportamento de enfrentamento são as ações de uma pessoa diante de um problema percebido na tentativa de adquirir alívio, gratificação ou tranquilidade (Weisman \& Worden, 1976-1977). Portanto, trata-se de um processo adaptativo no qual os fatores ambientais que possibilitam respostas específicas podem ser modificados. 
Nesse contexto, considerando o luto como um processo que exige elaboração psíquica e enfrentamento de uma perda significativa sabe-se que a presença de uma rede de suporte eficiente facilita no enfrentamento da experiência de indivíduos enlutados (Mazorra, Franco, \& Tinoco, 2002; Parkes, 1998). Já a falta de suporte social é considerada um fator de risco para luto complicado (Parkes, 1998; Stroebe \& Schut, 2001).

A necessidade de suporte pode ser identificada já no período da doença. Um estudo mostrou que adolescentes com câncer têm dificuldade em falar sobre a morte, embora demonstrem sentimentos de preocupação e medo, principalmente conforme veem a progressão da doença (Menossi, Zorzo, \& Lima, 2012). Portanto, entender os sentimentos e as formas de expressar esses sentimentos retraídos pode ajudar os profissionais a se aproximarem das experiências de morte/morrer de pacientes e familiares, reconhecendo o ambiente virtual como um meio de comunicação que impulsiona elementos importantes para a elaboração do luto.

Assim, considera-se que os resultados deste estudo possam ajudar na compreensão do uso do Facebook, nas situações de luto, nos tempos atuais.

\section{Objetivos}

Explorar a utilização da rede social Facebook quando há morte de um ente querido e analisar o compartilhamento de conteúdos no perfil do falecido, postumamente mediada por esta plataforma.

\section{Método}

Trata-se de um estudo descritivo, exploratório com abordagem qualitativa. Para a coleta dos dados foi necessária a inserção dos pesquisadores no Facebook. Isso possibilitou a obtenção de informações realmente pertinentes ao conteúdo da pesquisa, selecionando possíveis participantes de acordo com os critérios de seleção. Para tanto, o participante deveria ter uma página de usuário do Facebook na qual fosse anunciado (postado) o seu falecimento e, ainda, esse usuário deveria estar ativo na rede social durante 0 último mês anterior à morte.

Assim, depois de selecionado o provedor de serviço da Internet que seria estudado - Facebook - passamos a observar as interações entre seus membros a fim de se obter alguma informação sobre a identidade cultural dos integrantes.

Do mesmo modo que acontece no mundo real, ao se investigar as informações do ambiente online também é preciso observar a ética (Kozinets, 2007). Dessa forma, esta pesquisa, por envolver seres humanos, foi submetida à apreciação do Comitê de Ética em Pesquisa da Escola de Enfermagem da Universidade de São Paulo-USP/SP, tendo sido aprovada. Esse parecer está disponível no Sistema Nacional de Ética em Pesquisa (SISNEP), protocolo $\mathrm{n}^{0}$ 1.088/2011.
Ao refletir sobre a relação entre privacidade e respeito à integridade individual na prática da pesquisa na Internet, Elm (2009) classifica os ambientes online em quatro níveis de privacidade que, embora não constituam categorias estanques, seriam discerníveis. São eles: público (aberto e disponível a todos); semipúblico (requer cadastro ou participação); semiprivado (requer convite ou aceitação) e privado (requer autorização direta). Sendo assim, há a possibilidade de trabalhar os dados encontrados na rede, conforme o tipo de situação na qual foram disponibilizados. A publicação de dados ou opiniões em um sistema aberto ou semipúblico implica que estes podem ser trabalhados e divulgados pelos pesquisadores, sem a necessidade de autorização das pessoas que os originaram ou daquelas às quais as publicações dizem respeito, perspectiva a qual vem sendo comumente adotada no Brasil. Elm (2009) argumenta sobre a necessidade de se atentar para as diferenças culturais e geracionais na compreensão do que é a privacidade e do valor que a ela é conferido.

Para o tratamento dos dados, utilizou como método a análise de conteúdo, que busca interpretar os dados, por meio de uma descrição objetiva e sistemática do conteúdo manifesto da comunicação (Bardin, 2009). No processamento dos dados, após a seleção das postagens relacionadas com os objetivos desta pesquisa, preparou-se o material para análise visando descobrir os núcleos de sentido que compõem a comunicação e cuja presença ou frequência de aparição podem ser significativos ao objetivo analítico escolhido (Bardin, 2009).

Inicialmente, foi realizada a pré-análise para codificação aberta, que diz respeito, especificamente, a nomear e classificar o material pelo exame exaustivo dos dados, quebrando o conteúdo em pequenas frases, para posterior categorização e interpretação. Dessa forma, as postagens foram agrupadas, lidas e reorganizadas por similaridade, constituindo as categorias que representam a utilização da rede social Facebook por enlutados pela morte de um ente querido.

Durante a coleta e análise dos dados, procedimentos foram adotados para garantir a proteção da privacidade e sigilo das informações, de forma que não pudessem ser identificados os dados de autoria e a identidade real do participante da pesquisa. Durante a realização deste estudo, os pesquisadores estiveram atentos às recomendações sobre ética em pesquisa na Internet, sendo atualmente norteados pelas diretrizes de um grupo multicultural (Association of Internet Researchers - AoIR), que produziu o documento: Ethical decision-making research: recommendations from the AoIR ethics working committee (Ess \& Association of Internet Researchers, 2002).

A pesquisa foi desenvolvida no Facebook, mais precisamente, na página de um usuário falecido. Este foi identificado por fazer parte do núcleo de amigos de um dos pesquisadores. As informações a respeito do falecido serão restritas às informações contidas no perfil dele. Vale ressaltar que essas informações estão publicamente disponíveis, uma vez que houve o consentimento dos usuários 
quando aceitaram os termos do Facebook no momento do contrato de uso e privacidade.

O usuário era um senhor de 88 anos na data de sua morte, foi casado e teve dois filhos. Apresentava-se como judeu, trabalhava na área da Educação e tinha 5.184 amigos na rede social analisada. A sua última postagem havia sido seis dias antes da data do falecimento. Atendendo aos objetivos do estudo, selecionamos apenas as postagens relacionadas ao falecimento do usuário em que foram analisados 195 discursos postados na página do falecido durante o primeiro mês da morte do mesmo.

\section{Resultados}

Os resultados ilustram como ocorre a utilização e o compartilhamento na rede social Facebook em um evento de luto de um amigo. Os sobreviventes, amigos do falecido, ao longo de um mês após a data do falecimento, postaram uma variedade de conteúdo relacionado à sua relação com o falecido, reações emocionais e cognitivas específicas da morte, bem como sua experiência de vida e de luto. Ao longo do primeiro mês foi possível observar que as postagens tornaram-se menos frequentes e com menos reações emocionais. Foram identificadas quatro categorias temáticas: expressar reações emocionais e cognitivas à morte; manterse conectado ao falecido; divulgar homenagens, eventos e agradecimentos e expressar condolências aos familiares.

Essas categorias temáticas são representadas por discursos dirigidos ao falecido; comunicação direta com a família dele e discurso público, especialmente anunciando rituais ou celebrações relacionadas à tradição da religião do falecido. A seguir, apresentamos cada uma das categorias temáticas.

\section{EXPRESSAR REAÇÕES EMOCIONAIS E COGNITIVAS À MORTE}

Alguns comentários foram categorizados como indicadores das estratégias de enfrentamento emocional ou cognitivo que evidenciam diferentes reações frente à notícia da morte do amigo. Tais comentários relacionavam-se especialmente a negação ou aceitação da morte do falecido com variações nas intensidades das emoções exibidas e na profundidade da dor. Os comentários que aparecem nessa categoria estão direcionados tanto ao falecido como ao público, isto é, sem indicar uma conversa com o amigo morto:

Querido professor, fiquei muito triste quando soube de seu falecimento...

Uma perda irreparável, muito triste...

Uma grande perda...

Lamentei muito!

Com muita tristeza que recebi a notícia do falecimento do querido professor.

$\mathrm{O}$ atordoamento demonstrando a surpresa e negação à notícia também estão presentes:
Como assim???

Estou chocada!!!!

MEU DEUS!!

Não acredito!

Ao expressar a dor pela perda do amigo, os usuários, por vezes, também dão algum significado a tal dor:

Ele está feliz agora, encontrando-se com sua amada.

Que triste, ele não conseguiu ficar longe da sua amada...

Almas gêmeas não podem ficar muito tempo separadas!

...sua jornada e missão foram cumpridas com sucesso e deixou saudades e ensino.

\section{MANTER-SE CONECTADO AO FALECIDO}

A rede social oferece, também, a possibilidade dos amigos se conectarem e se comunicarem com a pessoa que morreu. Essa categoria temática diz respeito à manutenção de uma comunicação direta, postada ao falecido, manifestando admiração, lembranças de fatos ocorridos durante a vida, ressaltando o papel importante que o falecido teve na vida dos amigos, dizendo adeus e pedindo ao falecido que os ilumine. A página do falecido oferece um espaço para os amigos expressarem seu sofrimento abertamente, em um local onde outros também colocam seus pensamentos e sentimentos:

Vocês estão em nossos corações, agora mais do que nunca, prova disto é que estamos aqui em seu Facebook .... tenham muita luz, onde estiverem... Professor amigo, querido...

Continue nos iluminando do lado de lá, caro Professor!

Obrigada por tudo mesmo!

Valeu, Professor! A "LUZ" que espalhou por aqui frutifica e seu exemplo permanece!...

$\mathrm{Eu}$ não vou esquecer nunca do senhor, o senhor marcou a minha infância e a de muita gente! Homem respeitável! Cumpriu muito bem a sua missão na Terra!

As manifestações de carinho e saudades também compõem esse tema:

Vou lembrar sempre dele!!

Deixará saudades.

Professor que deixou marcas, muitas lembranças.

Perdi um grande Mestre.

Era uma das poucas pessoas que entendeu (sic) minha dificuldade. Agradeci ele (sic) muito por isso. 


\section{DIVULGAR HOMENAGENS, EVENTOS E AGRADECIMENTOS}

A página do falecido é utilizada pelos familiares para notificar a morte, divulgar homenagens, rituais e fazer agradecimentos.

Este foi o primeiro comentário no dia da morte do falecido e foi postado por um membro da família:

Descanse em paz meu querido tio. familiar:

Alguns dias depois, outra postagem de um

Convidamos a todos para um Shabat Especial em memória ao Prof... ZL

Um dos filhos postou agradecimentos:

Gostaria de agradecer a emocionante homenagem... ao meu pai...

Obrigado a todos que me ajudaram a cuidar dele nessa jornada...

Além disso, homenagens póstumas como forma de reconhecimento e congratulações ao falecido também são encontradas nas postagens. Os usuários expõem sua admiração e respeito pelo falecido e o homenageiam expondo suas qualidades. Ressaltam sua idoneidade, apreciam sua dedicação à profissão e à comunidade judaica. Também foram realizadas postagens de expressões hebraicas que honorificam o morto:

Um grande líder, um educador, uma pessoa de respeito. Grande líder, deixou um legado de amor...

Uma grande pessoa e grande ser humano! Nobre e dedicado a tudo que fazia. Seu nome será eternizado com o cumprimento de sua grande missão...

\section{EXPRESSAR CONDOLÊNCIAS AOS FAMILIARES}

Também no Facebook as frases protocolares de condolências aos familiares se destacaram. Alguns usuários parecem perder a espontaneidade nas situações de luto ou preferem restringir-se às frases protocolares dos tradicionais funerais:

Meus sinceros sentimentos...

Meus sentimentos à família...

Minhas condolências à família

Meus sentimentos à Família e muita força.

Nossos mais profundos sentimentos!

Expressões menos formais também aparecem para o consolo da família:

Nosso carinho para a família!
Gostaria de deixar um abraço à família...

Que a família tenha força para superar esta grande perda...

Força à toda a família!

A religiosidade e espiritualidade estiveram presentes nessa categoria. O usuário falecido apresentava-se como judeu. Para o judaísmo, a palavra HaShem é uma forma para designar Deus fora do contexto da reza ou da leitura pública do texto bíblico. Esta palavra foi mencionada várias vezes nas postagens de condolências:

Que HaShem console todos os seus familiares!

Outra expressão convencional também ligada à religião e que faz referência à alma do falecido também foi utilizada pelos usuários:

\section{Baruch dayan emet.}

\section{Discussão}

O luto é o processo normal e esperado de elaboração psíquica e enfrentamento da vivência de perdas significativas, que implica na transformação e ressignificação da relação com o que foi perdido. Com a perda de um ente querido, há um vínculo internalizado que se mantém e é ressignificado ao longo do trabalho de luto (Mazorra, 2009).

Toda sociedade possui normas que regem não somente o comportamento de seus membros, mas também seu afeto, cognição e espiritualidade. Como parte dessas regras, há normas que estruturam o luto, que incluem comportamentos (rituais, expectativas de etiqueta), sentimentos, expressão e controle de afeto e espiritualidade esperados (Doka, 2008). Quando isso não acontece, há um desconforto ou até mesmo reprovação da rede de suporte.

Um estudo realizado com a aplicação de 1.304 questionários, em todas as capitais do Brasil, ao perguntar: "Qual deve ser o comportamento de uma pessoa em trabalho de luto?", obteve $77,6 \%$ das respostas indicando a discrição como desejável. Em outra questão do estudo: "Qual deve ser o comportamento de um indivíduo que mantenha vínculos de amizade, de trabalho ou outro com o enlutado?", 72,01\% responderam: "não importunar" e somente $18,71 \%$, "dar apoio" (Koury, 2003). Tal autor aponta que a sociedade brasileira urbana é caracterizada pelo refreamento das ações de partilha e expressão do sofrimento; mascaramento do morrer; distanciamento em relação ao morto e aos enlutados; receio social de contaminação em relação à dor do enlutado e vergonha de estar enlutado. Apesar de esse estudo não ser muito recente, pois foi realizado em 2003, entendemos que o pensamento atual é de que nossa sociedade ocidental, de um modo geral, nega a morte e tudo aquilo que pode fazer lembrar sua existência, 
não oferece continência ao enlutado, pelo contrário, procuram afastá-lo e excluí-lo.

Há uma série de fatores relacionados à elaboração do luto pela perda de um ente querido. A falta de empatia, suporte social e a exclusão dos rituais religiosos ou sociais para o luto tendem a intensificar as reações emocionais e colaborar para a complicação do processo. Nosso estudo mostra que as novas tecnologias e práticas interacionais podem contribuir para uma mudança na maneira da sociedade lidar com a morte e com o enlutado. Neste estudo, as interações que ocorreram com os comentários no perfil do falecido, direcionadas ao falecido, ao público, aos familiares e pelos familiares, nos fazem pensar que as redes sociais podem deslocar o luto de um espaço privado para um espaço público. Para os profissionais de saúde, configura-se um novo espaço de comunicação que permite acompanhar sentimentos e vínculos presentes e pode ajudar na construção de significados e na elaboração do próprio processo de luto ou dos pacientes e familiares.

O suporte social da comunidade familiar, religiosa e profissional recebido após a vivência da morte de um ente querido é um fator extremamente relevante para o enfrentamento do luto (Mazorra, 2009). A falta desse suporte é considerado um fator de risco para o luto complicado (Parkes, 1998; Stroebe \& Schut, 2001). Acreditamos que as novas tecnologias e práticas interacionais aproximam a comunidade do enlutado, e a rapidez na qual os comentários fluem, resulta em um acolhimento quase que imediato do enlutado. Isto pode ser notado na categoria "expressar condolências aos familiares". Apenas vinte minutos após o anúncio do falecimento, por um familiar, no perfil do falecido, as manifestações de apoio já se iniciaram. Nessa categoria, outra interação que deve ser ressaltada é a interação entre os próprios usuários com as "curtidas" em comentários feitos tanto para o público como para o falecido e seus familiares.

Constatamos que expressões subjetivas sobre a morte podem tornar as redes sociais um importante instrumento para os profissionais reconhecerem os sentimentos envolvidos no processo do enlutado. No entanto, devemos reforçar a importância do cuidado oferecido ser atento, não crítico e sensível ao enlutado, promovendo empatia e continência; caso contrário, o enlutado poderá continuar a sentir-se solitário em sua dor. Neste estudo, na categoria "divulgar homenagens, eventos e agradecimentos", ressaltamos que os comentários postados pelos usuários expõem sua admiração e respeito pelo falecido e o homenageiam destacando suas qualidades. Temos que nos atentar às críticas que possam desagradar e prejudicar os enlutados e suas reações. Nesse sentido, pensamos ser de extrema importância um projeto de educação para a morte (Kovács, 2003) e, em especial, de educação para o luto, no sentido de difundir o conhecimento a respeito desse processo e das necessidades do enlutado. Com isso, as redes sociais e comunidades online podem permitir que o enlutado sinta-se acolhido no enfrentamento de sua dor, tendo seu sentimento de desamparo diminuído.
Uma constatação interessante deste estudo foi identificar a linguagem usada nos comentários de alguns dos usuários que se dirigiam diretamente ao falecido. Esse fato aparece na categoria temática "manter-se conectado ao falecido". A princípio, pode ser considerado um comportamento inapropriado, que impede o enlutado de se dar conta da realidade da morte. No entanto, as expressões de continuidade do vínculo de procura pelo falecido pouco tempo após a ocorrência da morte são consideradas relativamente comuns e não necessariamente mal adaptativas (Field, 2008). As crenças religiosas e culturais do enlutado em relação à vida após a morte pode ajudar a avaliar se determinado tipo de expressão de vínculo continuado indica dificuldade em lidar com alguma situação de sofrimento (Bousso, Serafim, \& Misko, 2010). A crença na existência continuada do espírito, como no caso do judaísmo, religião adotada pelo falecido, precisa ser respeitada antes de se considerar postagens como evidências de perda não resolvida, tendo em vista que há uma transformação na relação com o falecido, antes e após a morte (Field, 2008). No presente estudo, os usuários dirigiram comentários ao falecido recordando experiências passadas, ou de despedida ou como uma nova forma de se relacionar, pedindo ao falecido que cuidasse do sobrevivente.

A construção de significados atribuídos à morte pelo enlutado é apontada por diversos autores como central no processo de elaboração do luto (Franco, 2008; Neimeyer, 2001). No entanto, pouco é encontrado a respeito de quais são esses significados e como eles facilitam ou dificultam o processo de elaboração (Mazorra, 2009). Ao longo deste trabalho, na categoria temática "expressar reações emocionais e cognitivas à morte", identificamos alguns possíveis significados construídos a respeito da morte do ente querido nos comentários de alguns dos enlutados. Tal processo se dá, por meio da narrativa (Neimeyer, 2001) que organiza o discurso e a experiência vivida, cria as histórias temporalmente e dá sentido aos acontecimentos, em um contexto social, de acordo com as crenças religiosas e culturais (Bousso et al., 2010). Portanto, embora os comentários postados não sejam narrativas completas, podemos considerá-los como parte de narrativas pessoais que encontram suporte no domínio social (Neimeyer, 2001).

Estudos anteriores identificaram interações pessoais como um mecanismo de enfrentamento eficaz em resposta ao estresse e trauma (Pennebacker \& Harber, 1993) e sites online de redes sociais ou blogs foram utilizados, principalmente, para autoexpressão criativa e para compartilhar experiências pessoais (Lenhart \& Foz, 2006). Com isso, as oportunidades ilimitadas para expressar pensamentos pessoais e sentimentos bem como a interação com outras pessoas usando a rede social Facebook, pode auxiliar no processo de luto quando morre um amigo ou ente querido. Além disso, vários comentários observados no presente estudo suportam a literatura encontrada. 
O enlutado precisa falar sobre a morte do seu ponto de vista e também sobre o seu processo de luto para encontrar sentido nela (Mazorra, 2009). As redes sociais propiciam este espaço e amigos próximos do falecido são importantes na construção de redes de apoio. Assim, a Internet pode ser considerada uma comunidade na qual o conteúdo postado afeta os membros individualmente, propiciando um contexto de enfrentamento àqueles que vivenciam o luto.

Um estudo examinou como o luto é expresso por jovens na Internet, mais especificamente no site de relacionamentos Orkut, discutindo a importância do espaço virtual nas relações de luto e perda (Peruzo, Jung, Soares, \& Scarparo, 2007). O resultado aponta que, de fato, a Internet possui um papel importante na elaboração do luto por jovens, embora não tenha ficado explícito se essa estratégia de elaboração é positiva ou negativa para eles. Esta última afirmação consiste na ideia implícita de que cada pessoa é única e possui um contexto particular, não sendo possível generalizar que a Internet seja eficiente ou não para a superação do luto.

Neste sentido, apontamos a importância de que futuros trabalhos investiguem a relação entre as expressões de continuidade do vínculo e sua relação com o ajustamento à morte de um ente querido quando este faz uso de redes sociais ou ambientes interacionais online.

\section{Conclusão}

Com base na literatura prévia, explicando os processos de enfrentamento humano e as respostas ao luto, os resultados deste estudo permitem afirmar que os sites de redes sociais online podem facilitar o enfrentamento do luto não só como um espaço de expressão com liberdade de discurso e possibilidade de suporte social, mas também por oferecer a oportunidade de interações que ajudam a refletir sobre sua relação com o falecido e suas próprias emoções. Sendo assim, abre-se a possibilidade para ajudar os profissionais na aproximação das famílias e compreensão dos significados que envolvem o processo de elaboração do luto desses familiares, dos pacientes e mesmo dos profissionais.

Verificou-se que há diversidade de sentimentos expressos por meio das redes sociais, além de transformação de limites evidente, o que permite aos seus usuários tratarem de assuntos até então privados. Isso demonstra $o$ fato de que as redes virtuais podem se constituir como um campo de estudos importante, principalmente por permitir a manifestação de temas considerados tabus e que dificilmente são tratados abertamente, como a morte e o morrer.

\section{Facebook: A new locus for the manifestation of a significant loss}

Abstract: The purpose of this study was to explore the use of the social network Facebook by users after the death of a loved one and analyse the sharing of contents of the deceased user profile. This is a qualitative study and content analysis was used for data treatment. 195 comments posted were analyzed in the deceased user profile during the first month after death. It was possible to identify thematic categories that include comments to the deceased, feelings, emotions, mourning coping strategies indicators, religious beliefs and tributes. Virtual social networks allow the manifestation of feelings usually retract and the interaction of social issues, that are hardly treated openly, favouring the elaboration of mourning by patients, families and professionals facing the death/dying and mourning process.

Keywords: grief, internet, social interaction.

\section{Facebook: un nouveau locus pour la manifestation d'une perte importante}

Résumé: Les objectifs de cette étude étaient d'examiner l'utilisation du réseau social Facebook par des utilisateurs ayant perdu un être cher et d'analyser le partage de contenu dans le profil de la personne décédée à titre posthume modéré par cette plateforme. II s'agit d'une étude qualitative qui a utilisé l'analyse de contenu pour le traitement des données. 195 commentaires postés sur le profil à titre posthume pendant le premier mois après la mort ont été analysés. II a été possible d'identifier des catégories thématiques des commentaires à la personne décédée; les sentiments, les émotions, les indicateurs des stratégies d'adaptation de deuil, les croyances et les honneurs religieux. Les réseaux sociaux virtuels impulsionnent l'expression des sentiments généralement rétractés et permettent que les questions difficiles d'interaction sociale soient traitées ouvertement en faveur de l'élaboration du deuil pour les patients, les familles et les professionnels qui confrontrent le processus de la mort / mourir et du deuil.

Mots-clés: deuil, internet, interaction sociale. 


\section{Facebook: un nuevo locus para la manifestación de una pérdida significativa}

Resumen: Los objetivos de este estudio fueron explorar el uso de los usuarios de la red social Facebook por la muerte de un ser querido y analizar el intercambio de contenidos en el perfil de la persona fallecida, administrado por esta plataforma. Se trata de un estudio cualitativo que utilizó el análisis de contenido para el procesamiento de datos. Fueron analizados 195 comentarios en el perfil de la persona fallecida, durante el primer mes de su muerte. Se identificaron categorías temáticas como comentarios a la persona fallecida, sentimientos, emociones, estrategias de afrontamiento del proceso de la pérdida, creencias religiosas y homenajes. Las redes sociales virtuales impulsan la expresión de los sentimientos normalmente retraídos, permiten la interacción social de temas no tratados claramente y facilitan el afrontamiento de la pérdida para pacientes, familiares y profesionales.

Palabras-clave: luto, internet, interacion social.

\section{Referências}

Bardin L. (2009). Análise de conteúdo. Lisboa: Edições 70.

Bousso, R. S., Serafim, T. S., \& Misko, M. D. (2010). Histórias de vida de familiares de crianças com doenças graves: relação entre religião, doença e morte. Revista Latino-Americana de Enfermagem, 18(2), 11-17.

Doka, K. (2008). Disenfranchised grief in historical and cultural perspective. In M. Stroebe, R. O. Hansson, H. Schut \& W. Stroebe (Eds.), Handbook of bereavement research and practice: Advances in theory and intervention (pp. 223-40). Washington, DC: American Psychological Association.

Educause Learning Initiative - ELI. (2007). 7 things you should know about Facebook II. Recuperado de http:// net.educause.edu/ir/library/pdf/ELI7025.pdf

Elm, M. S. (2009). How do various notions of privacy influence decisions on qualitative Internet research? In A. N. Maekman \& N. Baym (Eds.), Internet inquiry: Conversations about method (pp. 69-87). Los Angeles: Thousand Oaks, CA, Sage.

Ess, C., \& AoIR Ethics Working Committee. (2002). Ethical decision-making and Internet research: Recommendations from the AoIR ethics working committee. Recuperado de http://www.aoir.org/reports/ ethics.pdf

Field, N. P. (2008). Whether to relinquish or maintain a bond with the deceased. In M. Stroebe, R. O. hansson, H. Schut \& W. Stroebe (Eds.), Handbook of bereavement research and practice: 21st century perspectives (pp. 133-162). Washington, DC: American Psychological Association.

Franco, M. H. P. (2008). Trabalho com pessoas enlutadas. In M. M. M. J. Carvalho et al., (Orgs.), Temas em psico-oncologia (pp. 398-402). São Paulo, SP: Summus.

Koury, M. G. P. (2003). Sociologia da emoção: o Brasil urbano sob a ótica do luto. Petrópolis, RJ: Vozes.

Kovács, M. J. (2008). Educação para a morte. Desafio na formação de profissionais de saúde e educação. São Paulo, SP: Casa do Psicólogo.

Kozinets, R. V. (2007). Netnography 2.0. In R. W. Belk,
Handbook of qualitative research methods in marketing (pp. 129-42). Northampton, MA: Edward Elgar.

Lazarus, R. S., \& Folkman, S. (1984). Stress, appraisal and coping. New York: Springer.

Lenhart, A., \& Fox, S. (2006). A portrait of the Internet's new storytellers. Washington, DC: Pew Internet and American Life Project. Recuperado de http:/www. pewinternet.org/ /media/Files/Reports/2006/PIP\%20 Bloggers\%20Report\%20July\%2019\%202006.pdf.pdf

Mazzorra, L. (2009). A construção de significados atribuídos à morte de um ente querido e o processo de luto (Tese de Doutorado). Pontifícia Universidade Católica de São Paulo, São Paulo.

Mazorra, L., Franco, M. H. P., \& Tinoco, V. (2002). Fatores de risco para luto complicado numa população brasileira. In M. H. P. Franco (Org.), Estudos avançados sobre o luto (pp. 39-60). Campinas, SP: Livro Pleno.

Menossi, M. J., Zorzo, J. C. C., \& Lima, R. A. G. (2012). A dialógica vida/morte no cuidado do adolescente com câncer. Revista Latino-Americana de Enfermagem, 20(1), 126-134.

Negrini, M. (2010). A morte no ciberespaço: um estudo etnográfico da comunidade do Orkut "Profiles de Gente Morta”. Discursos Fotográficos, 6(8), 13-33.

Neimeyer, R. (2001). Meaning reconstruction and the experience of loss. Washington, DC: American Psychological Association.

Parkes, C. M. (1998). Luto: estudos sobre a perda na vida adulta. São Paulo, SP: Summus.

Pennebacker, J. W., \& Harber, K. D. (1993). A social stage model of collective coping: The Loma Prieta Earthquake and the Persian Gulf War. Journal of Social Issues, 49(4), 125-145.

Peruzo, A. S., Jung, B. M., Soares, T., \& Scarparo, H. B. K. (2007). A expressão e a elaboração do luto por adolescentes e adultos jovens através da Internet. Estudos e Pesquisas em Psicologia, 7(3), 449-461.

Silvestre, J. C., \& Aguilera, N. V. (2008). Morte e luto no ciberespaço. In Anais online do II Simpósio Nacional da Associação Brasileira de Pesquisadores em Cibercultura. São Paulo: CENCIB/PUC-SP. Recuperado 
de http://www.cencib.org/simposioabciber/PDFs/CC/ Nuricel\%20Villalonga\%20Aguilera\%20e\%20Jose\%20 Carlos\%20Silvestre.pdf

Stroebe, M., \& Schut, H. (2001). Models of coping with bereavement: A review. In M. Stroebe, R. O. Hansson, W. Stroebe \& H. Schut (Eds.), Handbook of bereavement research: Consequences, coping and care (pp. 375-403). Washington, DC: American Psychological Association Press.
Weisman, A. D., \& Worden, J. W. (1976-1977). The existential plight of câncer significance of the first 100 days. International Journal Psychiatry Medicine, 7, $1-15$.

Worden, J. W. (1998). Terapia do luto: um manual para profissional de saúde mental. Porto Alegre, RS: Artes Médicas. 